\title{
ESTUDO ERGONOMICO DA CARGA MENTAL E DE SINTOMAS OSTEOMUSCULARES RELACIONADOS AO TRABALHO EM UM TRIBUNAL JUDICIÁRIO FEDERAL
}

\section{ERGONOMIC STUDY OF MENTAL LOAD AND OSTEOMUSCULAR SYMPTOMS RELATED TO WORK IN A FEDERAL JUDICIAL COURT}

\author{
Aleson Belo da Silva* E-mail: aleson-belo@live.com \\ Amanda Braga Marques* E-mail: amanda bmarques@hotmail.com \\ Thiago Allan Marques de Macedo* E-mail: thiagomm@riachuelo.com.br \\ Marco Antonio Leandro Cabral* E-mail: mcabral2014@gmail.com \\ Ricardo Pires de Souza* E-mail: ripiso@gmail.com \\ *Universidade Federal do Rio Grande do Norte (UFRN), Natal, RN
}

\begin{abstract}
Resumo: Este estudo tem o objetivo de avaliar as condições ergonômicas dos servidores que atuam em serviços processuais do Tribunal Judiciário Federal, com sede no Nordeste Brasileiro, por meio da aplicação de ferramentas de avaliação de carga mental e de percepção de dores osteomusculares no contexto laboral. Com investigação focada nos domínios da ergonomia cognitiva e física por meio da demanda da organização que possui alto índice de absenteísmos ocasionados por fatores ergonômicos. Ademais, o estudo também investiga o regime do teletrabalho, realizado por mais de $50 \%$ dos servidores do quadro. A pesquisa foi desenvolvida por meio da aplicação do questionário NASA TLX, para avaliação de carga mental de trabalho no domínio da ergonomia cognitiva, e do questionário Nórdico para avaliação de sintomas osteomusculares, no domínio da ergonomia física. Os resultados revelam a necessidade de intervenção ergonômica e melhorias nas condições de trabalho para minimizar os impactos da atividade laboral nos colaboradores por meio de ações e programas de qualidade de vida no trabalho. Revelam também a necessidade de acompanhamento das atividades realizadas por meio do teletrabalho, com definição clara de processos e ações ergonômicas visando garantir o bem estar dos servidores presencialmente e em teletrabalho.
\end{abstract}

Palavras-chave: NASA TLX. Questionário Nórdico. Ergonomia. Serviço público.

Abstract: This study aims to evaluate the ergonomic conditions of civil servants who work in procedural services of the Federal Judicial Court, headquartered in Brazil, through the application of tools for assessing mental load and perception of musculoskeletal pain in the work context. With research focused on the domains of cognitive and physical ergonomics through the demand of the organization that has a high rate of absenteeism caused by ergonomic factors. In addition, the study also investigates the teleworking regime, carried out by more than $50 \%$ of the staff on the board. The research was developed by the application of the NASA TLX questionnaire, for the assessment of mental load of work in the field of cognitive ergonomics, and the Nordic questionnaire for the evaluation of musculoskeletal symptoms, in the field of physical ergonomics. The results reveal the need for ergonomic intervention and improvements in working conditions to minimize the impacts of work activity on employees through actions and programs for quality of life at work. They also reveal the need to monitor the activities carried out by means of teleworking, with a clear definition of processes and ergonomic actions aimed at guaranteeing the well-being of the employees in person and in teleworking.

Keywords: NASA TLX. Nordic Quiz. Ergonomics. Public service. 


\section{INTRODUÇÃO}

A busca pela qualidade de vida no trabalho e redução de afastamentos tem mobilizado as organizações, sejam públicas ou privadas, a utilizarem a ergonomia como meio para alcançar o equilíbrio entre produtividade e saúde, o bem-estar humano e o desempenho global de sistemas como expressa a conceituação aprovada por unanimidade na Reunião do Conselho Científico da Associação Internacional de Ergonomia (International Ergonomics Association - IEA) (IEA, 2000).

Por meio da conceituação da IEA (2000), o objetivo da Ergonomia é assegurar ao trabalhador conforto, saúde e segurança no desempenho de suas atividades laborais, prevenindo contra os Distúrbios Osteomusculares Relacionados ao Trabalho (DORT) e distúrbios mentais, com atenção também à eficiência e eficácia dos processos por meio dos domínios da Ergonomia física, cognitiva ou organizacional.

Um estudo realizado pelo Saúde Brasil do Ministério da Saúde (2018) criou um alerta nas organizações após apresentar um aumento significativo das DORTs entre os anos de 2007 e 2016, sendo as doenças que mais acometeram os trabalhadores, com 67.599 casos. (BRASIL, 2018). Os registros de morbidade relacionado a esse problema cresceu $184 \%$, saindo de 3.212 casos durante o ano de 2007 para 9.122 em 2016, conforme Gráfico 1.

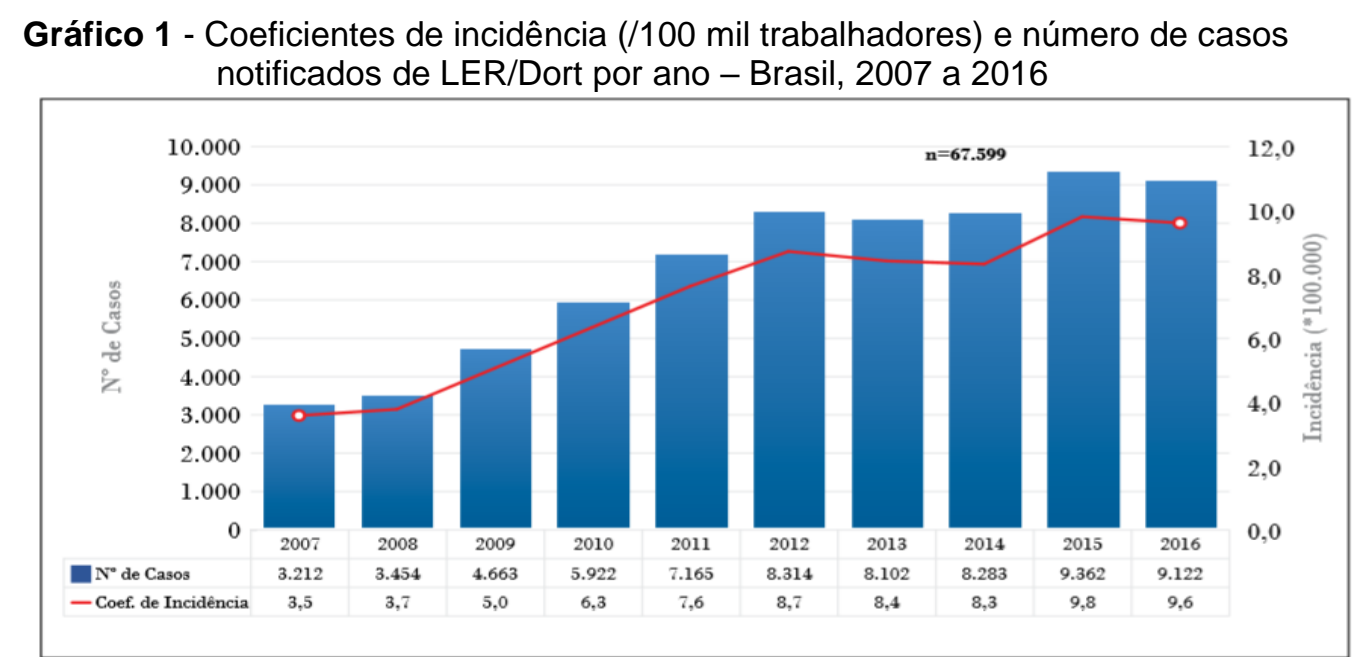

Fonte: Sinan/SVS/MS (2018).

O Gráfico 1 apresenta os coeficientes de incidência por 100 mil trabalhadores e número de casos de LER/DORT notificados por ano no Brasil, entre os anos de 
2007 a 2016. Para a realização do Gráfico foi utilizada a população economicamente ativa ocupada (PEAO) que se refere a pessoas acima de 10 anos de idade, ocupadas na semana de referência. Os dados das populações foram extraídos das tabelas disponíveis no sítio Sistema IBGE de Recuperação Automática (Sidra).

O Gráfico 1 revela a tendência de crescimento das notificações e que o maior incidente foi em 2015 com 9,8/100 mil trabalhadores com LER/DORT. Ainda de acordo com a pesquisa do Sinan (BRASIL, 2018), os maiores casos de notificação foram para o sexo feminino (189,5\%) em relação ao sexo masculino (178,6\%). Esse aumento pode refletir mudanças constantes nas organizações, nos processos laborais e até mesmo exposição a fatores de risco sem a devida prevenção.

O estudo do Saúde Brasil (2018) sobre o Panorama de Doenças Crônicas Relacionadas ao Trabalho no Brasil fornece também o Gráfico 2, que apresenta Coeficiente de incidência por 100 mil trabalhadores e número de notificações de transtornos mentais relacionados ao trabalho, por ano no Brasil entre 2007 a 2016.

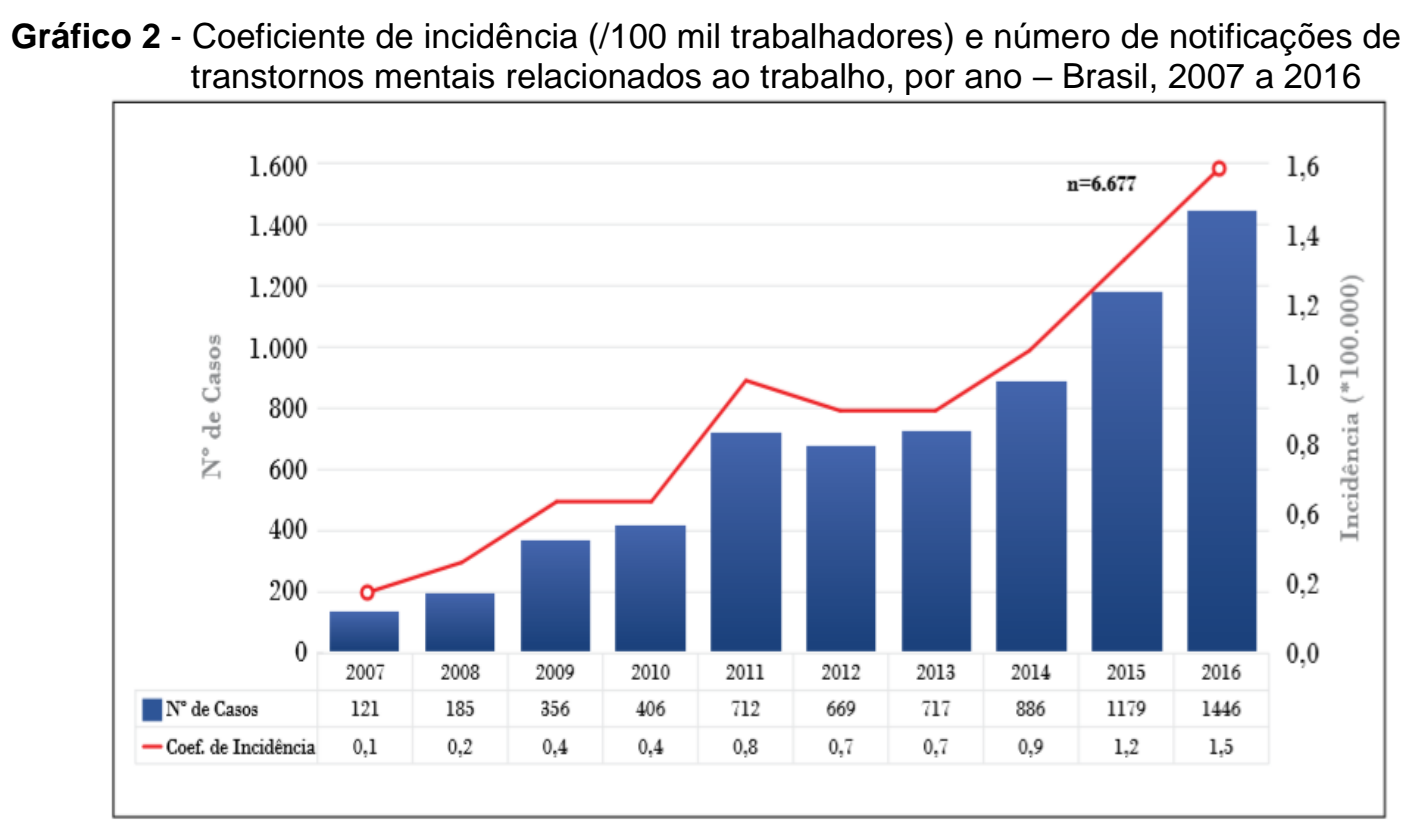

Fonte: Sinan/SVS/MS (2018).

Os dados do Gráfico 2 revelam que o coeficiente de incidência acumulado dos casos registrados de transtornos mentais relacionados ao trabalho, no período de 2007 a 2016, foi de 7 para cada 100 mil trabalhadores. A maior incidência ocorreu em 2016, apresentando 1,5 por 100 mil trabalhadores. Os dados também revelaram que os problemas foram mais recorrentes em trabalhadores do sexo 
feminino $(51,7 \%)$, entre 40 e 49 anos (33,6\%), e em indivíduos com ensino médio completo $(32,7 \%)$.

Desse modo, a Ergonomia se apresenta como meio para tentar reduzir os impactos ocasionados pela atividade laboral, por meio da abrangência de estudo e dos domínios que possui.

Entre as ferramentas ergonômicas de coleta de dados e análise tem-se 0 Questionário NASA Task Load Index (NASA-TLX) para mensuração de cargas percebidas no ambiente de trabalho e o Questionário Nórdico (NMQ), adaptado para as reais condições das instituições, buscando perceber os desconfortos e dores relacionadas ao trabalho, todos voltadas para percepção do trabalhador.

A aplicação do NASA TLX permite atuar por meio da ergonomia cognitiva por se ocupar dos processos mentais (percepção, memória e raciocínio, por exemplo), estudando a carga mental de trabalho. Já o Questionário Nórdico atende as necessidades da ergonomia física, ocupando-se das características humanas relacionadas com a atividade física, como a antropometria, fisiologia, entre outras características. Ambos os questionários são relevantes para a Ergonomia organizacional, terceiro domínio da ergonomia que trata de avaliar o ambiente e a interação com o homem, buscando ao mesmo tempo a produtividade esperada e a qualidade de vida desejada nas organizações.

Nesse contexto, o Tribunal Judiciário Federal, órgão público pertencente ao Poder Judiciário da $5^{\circ}$ região, com seis subseções, foi escolhida para a aplicação dos questionários para avaliar a situação acerca das cargas percebidas no trabalho e possíveis desconfortos físicos.

A unidade estudada iniciou em 2017 um projeto intitulado Programa de Ergonomia (PROERGO) vinculado ao setor de Qualidade de Vida do Trabalho da instituição, com o objetivo de melhorar as condições de trabalho dos servidores que desempenham suas atividades de forma sentada, com a utilização do computador em maior parte da jornada laboral. Além disso, os servidores precisam desempenhar suas atividades por meio de metas e prazos, precisando ter eficiência na execução dos processos.

O setor de qualidade de vida da unidade também realiza acompanhamento dos afastamentos para própria saúde, verificando quais as doenças que mais acometem os servidores. Também é realizado o acompanhamento das ações de 
qualidade de vida, tais como yoga, Pilates, Ginástica laboral, para minimizar os impactos do trabalho na vida dos indivíduos.

Sabendo da importância da garantia da qualidade vida para os servidores e a busca por uma análise fidedigna da situação ergonômica, sobretudo para fornecer informações relevantes sobre a percepção do serviço pelos servidores ao Programa de Ergonomia implantado com o objetivo de realizar intervenções em uma unidade do Poder Judiciário Federal, surge a seguinte situação problema da pesquisa: Como os questionários NASA TLX e Nórdico podem ser aplicados para a melhoria da qualidade de vida do Trabalho na unidade do Poder Judiciário Federal?

O trabalho tem como objetivo avaliar as condições ergonômicas dos servidores de um Tribunal Judiciário Federal localizado na região Nordeste do Brasil, por meio da aplicação de ferramentas de avaliação de carga mental de trabalho e de percepção de dores osteomusculares.

\section{FUNDAMENTAÇÃO TEÓRICA}

\subsection{Ergonomia}

O termo ergonomia tem sido amplamente discutido nas organizações, sejam públicas ou privadas, como sinônimo de melhoria das condições de trabalho. De acordo com lida (2005), a ergonomia é o estudo da adaptação do trabalho ao homem. Nesse sentido, trabalho é toda e qualquer situação em que exista um relacionamento entre homem e alguma atividade produtiva.

Avaliando do ponto de vista histórico, a Ergonomia foi desenvolvida como ciência propriamente dita, a partir da Segunda Guerra Mundial, (ALENCAR FILHO, 1993). lida (2002) ao argumentar sobre esse acontecido, relata que ao contrário de outras ciências que se perderam com o tempo e no espaço, a Ergonomia tem data de nascimento, 12 de julho de 1949.

A Associação Brasileira de Ergonomia (ABERGO, 2000) define que:

A Ergonomia objetiva modificar os sistemas de trabalho para adequar a atividade nele existentes às características, habilidades e limitações das pessoas com vistas ao seu desempenho eficiente, confortável e seguro (ABERGO, 2000).

No Brasil, a norma que contem diretrizes para a aplicação da Ergonomia é a NR 17 - Publicação: Portaria GM n.ํ 3.214, de 8 de junho de 1978, D.O.U. 06/07/78) 
(BRASIL, 2007). Esta norma estabelece parâmetros para adequar o ambiente de trabalho às condições psicofisiológicas do trabalhador, oferecendo conforto, autoestima e desempenho eficiente. Junto aos aspectos da NR 17- Ergonomia, temse a figura do ergonomista que tem o objetivo de contribuir com o bom planejamento de projetos, postos de trabalhos, avaliação de tarefas e ambientes, para que fiquem adaptados de acordo com as capacidades, necessidades e limitações do ser humano (ASSOCIAÇÃO INTERNACIONAL DE ERGONOMIA, 2000).

$\mathrm{Na}$ ergonomia existem diferentes ferramentas. Entre os instrumentos de avaliação para a ergonomia cognitiva, mais especificamente, para avaliação de carga mental de trabalho, destacam-se: a SWAT (COLLE; REID, 1998), o NASATLX (Task Load Index) desenvolvido por Hart e Staveland (1988), ERI (EffortReward Imbalance) desenvolvido por Johannes Siegrist (1996) e JSS (Job Stress Scale) desenvolvido por Robert Karasek. Os detalhes sobre essas ferramentas podem ser observados no Quadro 1.

\begin{tabular}{|c|c|c|}
\hline Método & Definições & Procedimentos \\
\hline & $\begin{array}{l}\text { Foi desenvolvido no laboratório de } \\
\text { pesquisas da NASA, em } 1987 . \\
\text { Tem como objetivo avaliar a carga } \\
\text { mental do trabalhador, observando } \\
\text { a duração da jornada, dor, sexo, } \\
\text { idade, nível de escolaridade e } \\
\text { tempo na função. É um } \\
\text { procedimento de taxa } \\
\text { multidimensional de (CARDOSO, } \\
\text { 2012) }\end{array}$ & $\begin{array}{l}\text { Provê uma pontuação global da Carga de } \\
\text { Trabalho baseada em uma média ponderada de } \\
\text { avaliações em seis subescalas: exigência } \\
\text { (demanda) mental, física, temporal, nível de } \\
\text { realização, de esforço e de frustração. Em estudo } \\
\text { de Cardoso (2012), este método apresentou-se } \\
\text { mais indicado para avaliar as dimensões } \\
\text { associadas à carga mental e para comparar os } \\
\text { resultados de diferentes sujeitos para uma mesma } \\
\text { tarefa (em comparação ao método SWAT) }\end{array}$ \\
\hline SWAT & $\begin{array}{l}\text { Em estudo realizado para revisar } \\
\text { este método, observou-se que o } \\
\text { mesmo é mais sensível para } \\
\text { avaliar a carga mental de trabalho } \\
\text { e a comparação de desempenho } \\
\text { do trabalhador em diferentes } \\
\text { atividades. Sua aplicação, por } \\
\text { contemplar maior número de } \\
\text { combinações (pesor das } \\
\text { dimensões), como cansativa } \\
\text { apontada cola } \\
\text { (CARDOSO, 2012). }\end{array}$ & $\begin{array}{l}\text { Utiliza técnica de medida conjunta que considera } \\
\text { que a carga mental de uma tarefa é medida em três } \\
\text { dimensões: tempo, esforço mental e estresse. } \\
\text { Essas dimensões são avaliadas por uma escala de } \\
3 \text { pontos para: normalmente, às vezes ou } \\
\text { raramente sobra tempo; pouca, moderada e } \\
\text { elevada exigência mental; e baixo, moderado e } \\
\text { elevado nível de estresse. Este método é aplicado } \\
\text { em duas fases: obtenção da escala de carga } \\
\text { mental de trabalho e avaliação dos níveis de carga } \\
\text { mental. }\end{array}$ \\
\hline
\end{tabular}


Quadro 1 - Métodos/ferramentas ergonômicas para avaliação de carga Mental

(conclusão)

\begin{tabular}{|c|c|c|}
\hline Método & Definições & Procedimentos \\
\hline ERI & $\begin{array}{l}\text { O método Effort-Reward Imbalance } \\
\text { é um modelo teórico da escala de } \\
\text { desequilíbrio entre esforço e } \\
\text { recompensa. É usado para medir o } \\
\text { nível de estresse a que o } \\
\text { trabalhador está } \\
\text { (HASSELHORN, 2004). }\end{array}$ & $\begin{array}{l}\text { O modelo ERI é construído a partir de um } \\
\text { questionário autorrespondido, contendo } 23 \text { itens em } \\
\text { sua versão reduzida, com respostas que utilizam } \\
\text { escala do tipo likert. Entretanto, o seu uso em } \\
\text { contextos internacionais é limitado pela língua, } \\
\text { exigindo, portanto, uma adaptação transcultural } \\
\text { Siegrist, 1996). O modelo ERI baseia-se na } \\
\text { reciprocidade de intercâmbio na vida profissional. } \\
\text { De acordo com o modelo, uma pessoa com maior } \\
\text { necessidade de controle responde de maneira } \\
\text { inflexível às situações de trabalho que exigem } \\
\text { muito esforço e oferecem baixa recompensa, } \\
\text { acarretando estresse e predispondo ao } \\
\text { adoecimento (THEORELL et al., 2000). }\end{array}$ \\
\hline JSS & $\begin{array}{l}\text { A Job Stress Scale é uma versão } \\
\text { resumida do questionário original } \\
\text { criado nos anos } 70 \text { por Robert } \\
\text { Karasek, um dos primeiros } \\
\text { pesquisadores a buscar a } \\
\text { existência de fatores estressores } \\
\text { no ambiente de trabalho e estudar } \\
\text { suas consequências sobre a saúde } \\
\text { do trabalhador (ALVES, 2004). }\end{array}$ & $\begin{array}{l}\text { A versão adaptada do Job Stress Scale é } \\
\text { constituída de } 17 \text { questões, divididas entre: } \\
\text { demanda psicológica, discernimento intelectual, } \\
\text { autoridade sobre decisões e apoio social } \\
\text { (THEORELL et al., 1996). }\end{array}$ \\
\hline $\begin{array}{l}\text { Análise } \\
\text { do } \\
\text { Apoio } \\
\text { Social } \\
\text { Familiar }\end{array}$ & $\begin{array}{l}\text { O NIOSH (2004) distingue um } \\
\text { conjunto de condições que pode } \\
\text { causar o estresse ocupacional, } \\
\text { entre eles está papel do apoio } \\
\text { social da família e sua interferência } \\
\text { na carga mental de trabalho. }\end{array}$ & $\begin{array}{l}\text { A versão adaptada das questões da ferramenta de } \\
\text { análise psicossocial do NIOSH recebe uma } \\
\text { pontuação (entre } 0 \text { e 4), com o intuito de verificar a } \\
\text { influência das condições familiares nos resultados } \\
\text { das metodologias de análise psicossocial (NIOSHI, } \\
\text { 2004). Assim, quanto maior o valor da escala, maior } \\
\text { o apoio social familiar no trabalho. }\end{array}$ \\
\hline
\end{tabular}

Fonte: Laperuta et al. (2018).

Dentre as ferramentas no Quadro 1, optou-se pela NASA TLX para a realização o presente trabalho. O NASA TLX é um método que foi desenvolvido pela Aerospace Human Factors Research Division da NASA, no seu centro de investigação de ames (HART; STAVENLAND, 1988). O termo carga de trabalho é construído com a necessidade de entender as exigências de cada atividade sobre as condições do trabalhador (FRUTUOSO; CRUZ, 2005)

O NASA TLX é um dos métodos utilizados para medir subjetivamente a carga de trabalho que foi originalmente proposto para avaliar a carga de trabalho mental (NASA, 1986). No entanto, sugerem que esse instrumento não mensura apenas a carga mental, mas a carga de trabalho de modo geral, uma vez que considera vários fatores que provocam impacto no trabalho, inclusive a carga física (DINIZ; GUIMARÃES, 2004; MÁSCULO; VIDAL, 2011).

O Quadro 2 apresenta os componentes de trabalho e suas definições, de acordo com o questionário NASA TLX.

Revista Produção Online. Florianópolis, SC, v. 21, n. 2, p. 631-653, 2021 
Quadro 2 - Componentes da carga de trabalho e suas definições, de acordo com o NASA-TLX

\begin{tabular}{|c|l|}
\hline $\begin{array}{c}\text { Componentes da } \\
\text { carga de trabalho }\end{array}$ & \multicolumn{1}{c|}{ Definição } \\
\hline Demanda Mental & Atividade mental requerida para realização do trabalho. \\
\hline Demanda Física & Atividade física requerida para realização do trabalho. \\
\hline Demanda temporal & $\begin{array}{l}\text { Pressão imposta na realização do trabalho, ou seja, para que se utilize o } \\
\text { menor tempo possível em uma tarefa e/ou se faça mais tarefas no menor } \\
\text { tempo. }\end{array}$ \\
\hline $\begin{array}{c}\text { Performance/Nível } \\
\text { de realização }\end{array}$ & Nível de satisfação com o desempenho pessoal na realização do trabalho. \\
\hline Nível de Esforço & $\begin{array}{l}\text { O quanto que se deve trabalhar, tanto no aspecto físico como mental, para } \\
\text { se atingir um nível desejado de desempenho. }\end{array}$ \\
\hline Nível de Frustação & $\begin{array}{l}\text { Fatores que inibem a realização do trabalho (insegurança, irritação, } \\
\text { estresse) ou influenciam a realização do trabalho. }\end{array}$ \\
\hline
\end{tabular}

Fonte: Ballardin; Guimarães (2009).

Já o Quadro 3 apresenta as principais ferramentas para avaliação de desconfortos físicos, do domínio da ergonomia física.

Quadro 3 - Ferramentas utilizadas para avaliação ergonômica

\begin{tabular}{|c|l|}
\hline Ferramentas & \multicolumn{1}{|c|}{ Descrição } \\
\hline $\begin{array}{c}\text { Avaliação Simplificada do } \\
\text { Fator Biomecânico (COUTO, } \\
\text { 1996) }\end{array}$ & $\begin{array}{l}\text { Avaliação da sobrecarga física; força; postura; posto e esforço } \\
\text { estático; repetitividade, organização e ferramenta de trabalho de } \\
\text { membros superiores. }\end{array}$ \\
\hline $\begin{array}{c}\text { Michigan (LIFSHITZ e } \\
\text { ARMSTRONG, 1986) }\end{array}$ & $\begin{array}{l}\text { Lista de avaliação das extremidades superiores dos indivíduos no } \\
\text { ambiente de trabalho. }\end{array}$ \\
\hline $\begin{array}{c}\text { Extremidade do Membro } \\
\text { Superior (KEYSERLING et } \\
\text { al., 1993) }\end{array}$ & $\begin{array}{l}\text { Análise das extremidades dos membros superiores separadamente } \\
\text { (esquerdo e direito). }\end{array}$ \\
\hline $\begin{array}{c}\text { OCRA (COLOMBINI et al., } \\
\text { 2005) }\end{array}$ & Caracterização da tarefa por sua frequência e esforço requerido. \\
\hline BORG (BORG, 1998) & $\begin{array}{l}\text { Estimativa da intensidade de esforço realizado relatado pelo } \\
\text { indivíduo. }\end{array}$ \\
\hline $\begin{array}{c}\text { CORLETT (CORLETT e } \\
\text { BISHOP, 1976) }\end{array}$ & $\begin{array}{l}\text { Avaliação de desconforto postural por meio de mapa de regiões } \\
\text { corporais. }\end{array}$ \\
\hline $\begin{array}{c}\text { RULA (MCATAMNEY e } \\
\text { CORLETT, 1993) }\end{array}$ & $\begin{array}{l}\text { Identificação de posturas e esforços que contribuem ao a } \\
\text { aparecimento de dores e lesões musculares em membros } \\
\text { superiores. }\end{array}$ \\
\hline $\begin{array}{c}\text { Strain Index (MOORE e } \\
\text { GARG, 1997) }\end{array}$ & $\begin{array}{l}\text { Avaliação do esforço classificando o nível do risco de } \\
\text { desenvolvimento de DORT. }\end{array}$ \\
\hline HSE (GRAVES et al., 2004) & $\begin{array}{l}\text { Avaliação gradativa à presença de exposições do risco de lesões } \\
\text { musculoesqueléticas em nível do membro superior. }\end{array}$ \\
\hline $\begin{array}{c}\text { Nordic Musculoskeletal } \\
\text { Questionnaire (KUORINKA } \\
\text { et al, 1987). }\end{array}$ & $\begin{array}{l}\text { Padronizar a mensuração de relato de sintomas osteomusculares } \\
\text { e, assim, facilitar a comparação dos resultados entre os estudos. }\end{array}$ \\
\hline
\end{tabular}

Fonte: Ligeiro (2010).

Com base nas informações do Quadro 3, escolheu-se para a aplicação o Nordic Musculoskeletal Questionnaire, ou questionário Nórdico (NMQ). Esse questionário foi desenvolvido com a proposta de padronizar a mensuração de relato 
de sintomas osteomusculares e, assim, facilitar a comparação dos resultados entre os estudos. (KUORINKA et al., 1987).

Na concepção de Ferrari (2006) o Questionário Nórdico é um dos principais instrumentos utilizados para analisar sintomas musculoesqueléticos em um contexto de saúde ocupacional ou ergonômico. Em relação a versão brasileira deste instrumento que foi proposta por Barros e Alexandre (2003) os diversos estudos obtiveram resultados satisfatórios. Sobre isso, Pinheiro et al. (2002) ao proporem em seu estudo intitulado "Validação do Questionário Nórdico de Sintomas Musculoesqueléticos (NMQ) como medida de Morbidade", concluíram, que a versão brasileira do NMQ apresentou bom índice de validade e recomenda sua utilização como medida de morbidade osteomuscular. Sendo, portanto, escolhido para a aplicação no presente estudo.

\subsection{Ergonomia no Serviço público}

De acordo com Cavalcante (2016), os servidores públicos, assim como os trabalhadores em geral, apresentam alguma queixa quanto às suas atividades laborais: rotina de trabalho, subutilização de suas potencialidades (talentos), condições inadequadas de trabalho, clima organizacional negativo, estagnação, falta de autonomia e reconhecimento, dentre outras. Observa-se que assim como na iniciativa privada, os servidores públicos estão expostos a peculiaridades do contexto laboral e, assim, faz-se necessária a inclusão de instrumentos de qualidade de vida no trabalho no âmbito do serviço público. (CAVALCANTE, 2016).

$\mathrm{Na}$ busca de eliminar a lacuna, o Ministério do Planejamento, Orçamento e Gestão intensificou a produção de Normativas para atender essa demanda do servidor público, A evolução das leis e demais regulamentações referentes às relações de trabalho entre o a Administração Pública Federal são observadas no Quadro 4. 
Quadro 4 - Legislação da Saúde do Servidor Público Federal

\begin{tabular}{|c|c|c|}
\hline Ordenamento Jurídico & Dispõe sobre & Período \\
\hline Lei 8.080 & $\begin{array}{l}\text { Dispõe sobre as condições para a promoção, proteção } \\
\text { e recuperacão da saúde }\end{array}$ & 19/9/1990 \\
\hline Lei 8.112 & $\begin{array}{l}\text { Regime jurídico dos servidores públicos civis da } \\
\text { União, das autarquias e das fundações públicas } \\
\text { federais }\end{array}$ & $11 / 12 / 1990$ \\
\hline Lei 8.270 & Remuneração dos servidores & 17/12/1991 \\
\hline Lei 11.907 & $\begin{array}{l}\begin{array}{l}\text { Altera a Lei } 8.112 / 90 \\
\text { periódicos }\end{array} \\
\end{array}$ & 2/2/2009 \\
\hline Decreto 97.458 & $\begin{array}{l}\text { Regulamenta a concessão dos Adicionais de } \\
\text { Periculosidade e de Insalubridade }\end{array}$ & 11/1/1989 \\
\hline Decreto 877 & $\begin{array}{l}\text { Regulamenta a concessão do adicional de irradiação } \\
\text { ionizante }\end{array}$ & 20/7/1993 \\
\hline Decreto 6.833 & $\begin{array}{l}\text { Institui o Subsistema Integrado de Atenção à Saúde } \\
\text { do Servidor Público Federal - SIASS e o Comitê } \\
\text { Gestor de Atenção à Saúde do Servidor - CGASS }\end{array}$ & 29/4/2009 \\
\hline Decreto 6.856 & $\begin{array}{l}\text { Regulamenta os exames médicos periódicos de } \\
\text { servidores. }\end{array}$ & $25 / 5 / 2009$ \\
\hline Decreto 7.003 & Regulamenta a licença para tratamento de saúde & $9 / 11 / 2009$ \\
\hline Decreto 7.944 & $\begin{array}{l}\text { Promulga a Convenção no } 151 \text { e a Recomendação no } \\
159 \text { da Organização Internacional do Trabalho sobre } \\
\text { as Relações de Trabalho na Administração Pública, } \\
\text { firmadas em } 1978\end{array}$ & $6 / 3 / 2013$ \\
\hline Portaria № 1.675 & $\begin{array}{l}\text { MP Institui o Manual para os Serviços de Saúde dos } \\
\text { Servidores Civis Federais e recepciona a utilização } \\
\text { das Normas Regulamentadoras no } 7 \text { e no } 9\end{array}$ & 10/10/2006 \\
\hline Portaria Normativa $\mathrm{n}^{\circ} \mathrm{3}$ & MP Assistência à saúde suplementar do servidor & $30 / 7 / 2009$ \\
\hline Portaria Normativa $\mathrm{n}-4$ & MP Orientações sobre exame periódico & $15 / 9 / 2009$ \\
\hline Portaria 1.261 & $\begin{array}{l}\text { MP Institui os Princípios, Diretrizes e Ações em Saúde } \\
\text { Mental na Administração Pública Federal sobre a } \\
\text { saúde mental dos servidores. }\end{array}$ & $5 / 5 / 2010$ \\
\hline Portaria Normativa no 3 & $\begin{array}{l}\text { MP Norma Operacional de Saúde do Servidor - NOSS. } \\
\text { Implantar ações de vigilância aos ambientes e } \\
\text { processos de trabalho e promoção à saúde do } \\
\text { servidor. Comissão Interna de Saúde do Servidor } \\
\text { Público - CISSP }\end{array}$ & 7/5/2010 \\
\hline Orientação Normativa $n^{0} 3$ & MP Regulamenta a licença para tratamento de saúde & $23 / 2 / 2010$ \\
\hline Orientação Normativa no 6 & $\begin{array}{l}\text { MP Estabelece orientação sobre a concessão dos } \\
\text { adicionais de insalubridade, periculosidade, irradiação } \\
\text { ionizante e gratificação por trabalhos com Raios-X ou } \\
\text { substâncias radioativas. }\end{array}$ & $18 / 3 / 2013$ \\
\hline $\begin{array}{l}\text { Orientação Normativa no } \\
16 .\end{array}$ & $\begin{array}{l}\text { MP Aposentadoria especial para servidores que } \\
\text { exerceram atividades em condições especiais no } \\
\text { serviço público }\end{array}$ & 23/12/2013 \\
\hline
\end{tabular}

Fonte: Adaptado de Cavalcanti (2016).

Desse modo, observa-se a necessidade de ações no serviço público para a garantia da saúde e qualidade de vida, de ações que contribuam para a melhoria continua da saúde dos servidores públicos. 


\section{METODOLOGIA}

O campo de pesquisa é uma unidade do Poder Judiciário Federal, englobando as 6 subseções dessa unidade. A unidade estudada, quando da aplicação do estudo contava com 442 pessoas em seu corpo funcional, sendo servidores, estagiários e magistrados.

As atividades do órgão público são executadas por meio de computadores, para tratar processos ou, nos casos dos setores administrativos, dar suporte as varas federais. Os servidores atuam sete horas por dia, trabalhando em posição sentada, precisando utilizar a digitação constantemente, atender telefones e realizar reuniões.

Foram utilizados os questionários NASA-TLX e o Nórdico para 0 levantamento de dados. As vantagens do uso de questionário é que se utiliza menos pessoas para ser executado e proporciona economia de custo, tempo, viagens, com obtenção de uma amostra maior e não sofre influência do entrevistador, porém existem dificuldades de conferir a confiabilidade das respostas (MARCONI; LAKATOS, 1996; MATTAR, 1996).

A pesquisa foi o resultado da execução de etapas sequenciais, planejadas junto ao Núcleo de Gestão de Pessoas da unidade, como descritas a seguir:

I. Detalhamento dos objetivos da Pesquisa - Antes de iniciar a pesquisa em campo, definiu-se os procedimentos que seriam necessários para alcançar os objetivos da Instituição e do pesquisador em avaliar as condições ergonômicas do órgão público.

II. Reunião de planejamento - Após definição das ferramentas, foi realizado uma reunião com a diretora do Núcleo de Gestão de Pessoas da unidade para apresentar as etapas da pesquisa. Os questionários foram submetidos a avaliação do setor de legislação e aprovados para serem aplicados, mediante calendário de aplicações.

III. Aplicação dos Questionários - Durante os meses de janeiro de 2020 a maio de 2020, todas as subseções da unidade foram visitadas aplicando os dois questionários em meio físico impresso. É válido salientar que buscou-se evitar influencias às respostas dos questionários.

IV. Tabulação e validação dos dados - Após a aplicação dos questionários, os dados foram tabulados em planilhas de cálculo para serem analisadas. 
V. Análise das respostas - Com a tabulação foi possível gerar indicadores e avaliar as respostas, encontrando resultados. As respostas foram analisadas por meio de software com ferramentas de cálculo.

VI. Considerações finais - A última etapa da pesquisa consistiu na elaboração de relatório e entrega ao setor de qualidade de vida, com os indicadores e resultados gerados, conforme também se encontra nesse estudo.

\section{RESULTADOS E DISCUSSÕES}

A unidade de estudo possibilitou a pesquisa com o objetivo de avaliar o ambiente e as relações de trabalho para reduzir os afastamentos por motivo de saúde, bem como os custos inerentes ao adoecimento dos funcionários. Com isso, as ferramentas de diagnóstico utilizadas no presente trabalho mostraram-se como um complemento para um diagnóstico mais evidenciado das situações que estão acometendo as pessoas do órgão.

A Figura 1 apresenta um dos postos de trabalho das subseções. Esse posto é semelhante a todos os demais, tendo em vista a realização de atividades administrativas.

Figura 1 - Posto de Trabalho da unidade de estudo

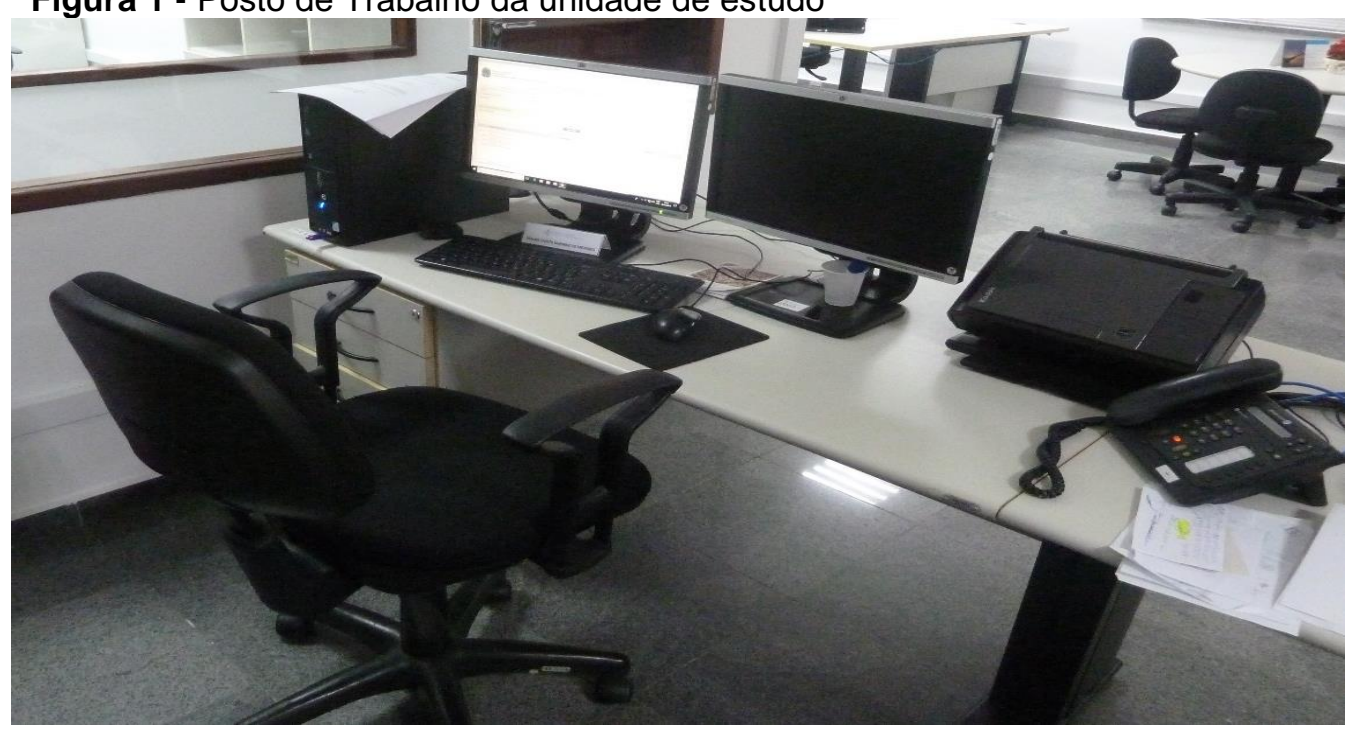

Fonte: Registro realizado pelos autores (2021).

A atividade fim do órgão é o processamento e o julgamento de ações onde a União, autarquias ou empresas públicas são partes interessadas. Sendo assim, executam trabalhos de modo sentado, diante de monitores, tendo que utilizar 
frequentemente a digitação e o telefone para o exercício da atividade laboral, como se pode observar na Figura 1.

Diante dessa constatação e objetivando justificar a pesquisa no contexto da Unidade Judiciária Federal, foram coletadas informações de afastamentos para tratamento da própria saúde entre os anos de 2016 a 2018, buscando avaliar, por meio de indicadores, a situação em que a instituição se encontrava e para dar sustentação a pesquisa.

O Gráfico 3 apresenta os percentuais dos principais motivos de afastamentos referentes aos anos de 2016 a 2018, de acordo com a Classificação Internacional de Doenças - CID 10.

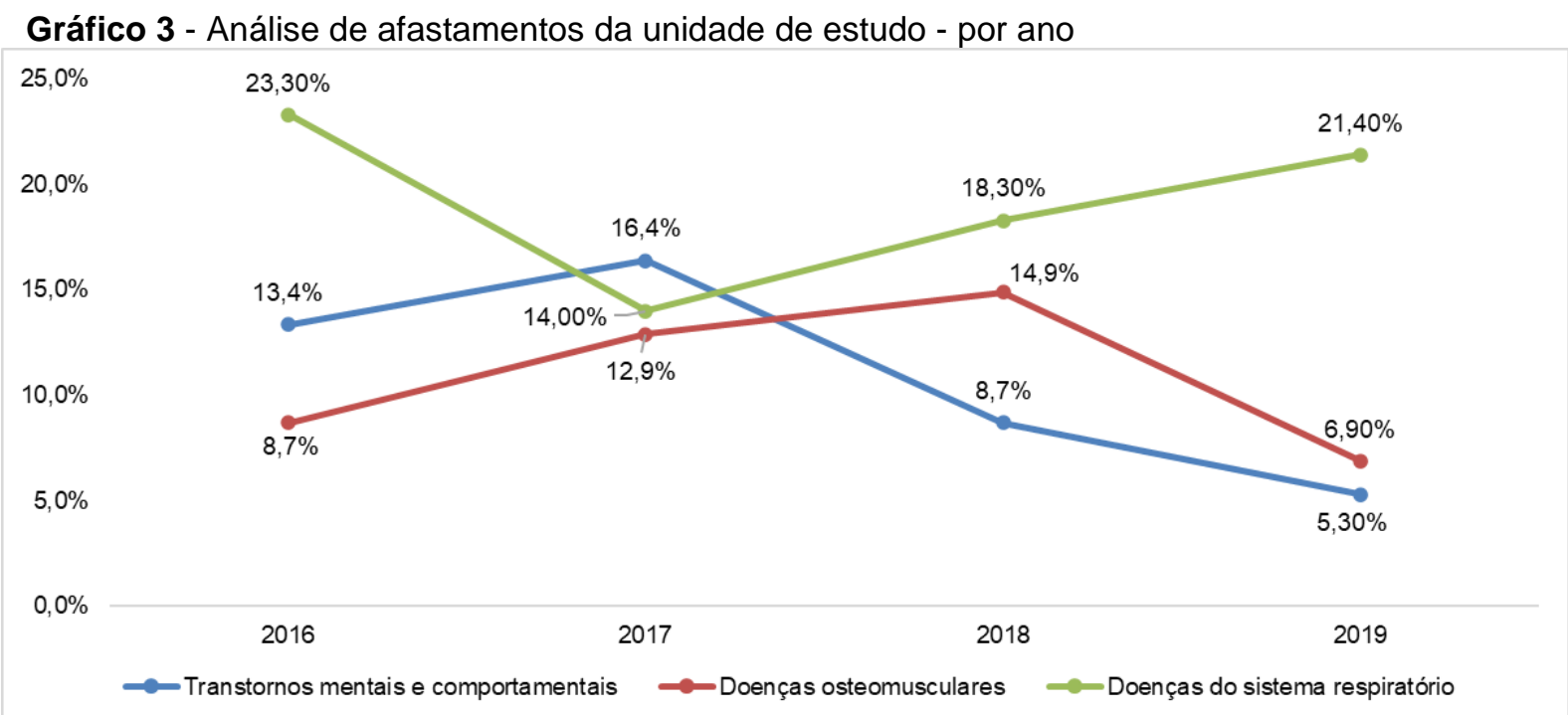

Fonte: Elaborado pelos autores (2021).

Em 2016, de acordo com Gráfico 3, os transtornos mentais e comportamentais obtiveram $13,4 \%$ dos afastamentos e os distúrbios osteomusculares obtiveram $8,7 \%$ do total. Já em 2017 , os transtornos mentais e comportamentais e os distúrbios osteomusculares (respectivamente, $1^{\circ}$ e $3^{\circ}$ lugar no ranking de afastamentos), foram os que mais afastaram os servidores.

Em 2018, houve uma redução dos índices de afastamentos relacionados a transtornos mentais e comportamentais, mas se pode ver que os distúrbios osteomusculares tem seus índices aumentados a cada ano, passando de 8,7\% em 2016 para $14,9 \%$ em 2019. Os afastamentos do trabalho geram dias perdidos, causam sobrecarga de trabalho para outros servidores e diminui o rendimento da organização, sendo, portanto, um indicador relevante estudo. 
Para a unidade de estudo, a aplicação dos ferramentais forneceu suporte para a percepção dos servidores quanto a carga de trabalho, incentivando na busca pela promoção e manutenção da qualidade de vida dos indivíduos e a adoção de medidas preventivas que contribuam para minimizar a ocorrência de doenças relacionadas a atividade laboral.

\subsection{Questionário NASA TLX}

O quantitativo de respostas ao questionário NASA TLX encontra-se na Tabela 1, explicitando o total de respondentes identificados por subseção e o total geral. Uma vez que a identificação era opcional, 10 servidores optaram por não identificar nem mesmo a subseção, núcleo ou vara ao qual faz parte. Dessa forma, a real porcentagem de respondentes nas subseções pode diferir da apresentada.

Tabela 1 - Quantitativo de respostas ao questionário NASA por unidade

\begin{tabular}{cccc}
\hline UNIDADE & TOTAL DE RESPOSTAS & COLABORADORES & RESPONDENTES (\%) \\
\hline Subseção 1 & 19 & 22 & $86,36 \%$ \\
Subseção 2 & 176 & 299 & $58,86 \%$ \\
Subseção 3 & 15 & 21 & $71,43 \%$ \\
Subseção 4 & 43 & 60 & $71,67 \%$ \\
Subseção 5 & 8 & 22 & $36,36 \%$ \\
Subseção 6 & 18 & 18 & $100,00 \%$ \\
Não identificado & 10 & - & - \\
Total & $\mathbf{2 8 9}$ & $\mathbf{4 4 2}$ & $\mathbf{6 5 , 3 8 \%}$ \\
\hline
\end{tabular}

Fonte: Elaborado pelos autores (2021).

Com base nas respostas dos 289 colaboradores, foi elaborada o Gráfico 4, cujo objetivo é explicitar os valores de cada carga de trabalho do ponto de vista dos respondentes.

Analisando o Gráfico 4, observa-se que a carga mental percebida pelos trabalhadores, de modo geral, é percebida como alta, tendo gradação média de 80 . Seguindo o mesmo perfil tem-se o nível de realização, com gradação média de 80 , a carga temporal com gradação média de 70 e o nível de esforço com 65. Em contrapartida, a exigência física é vista como baixa possuindo gradação média de 25. O nível de frustração apresenta uma gradação média de 45. 
Gráfico 4 - Respostas ao questionário NASA-TLX

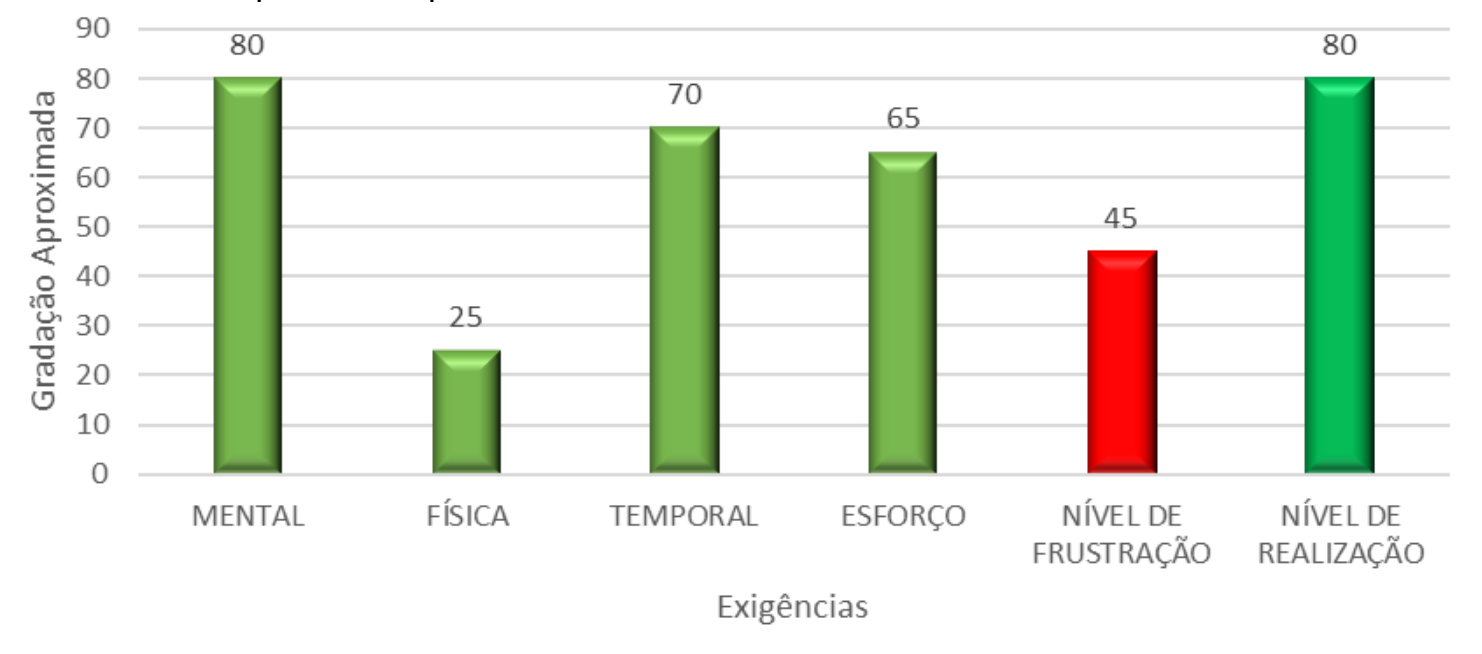

Fonte: Elaborado pelos autores (2021).

Pode-se verificar que a principal exigência percebida é a carga mental, condizendo com o esperado segundo à natureza das atividades laborais predominantes (analistas, técnicos, assessores e diretores). Tal exigência foi apontada como fator motivacional e desafiante na atividade, o que lhe atribui caráter positivo em relação à qualidade de vida do servidor.

O nível de realização elevado é importante indicador da satisfação dos colaboradores acerca de sua atividade de trabalho, sendo positivo à qualidade de vida. Esse dado indica que apesar das demais exigências e adversidades relatadas no ambiente de trabalho, a maior parte dos servidores é ou está realizado com a atividade desempenhada. Possíveis hipóteses para tal sentimento de realização podem ser: a adequada remuneração, flexibilidade de horário e projetos de qualidade de vida.

\subsection{Questionário Nórdico adaptado}

Assim como o Questionário NASA TLX, o questionário Nórdico foi aplicado conforme metodologia de aplicação na literatura. Percebe-se que cerca de $65 \%$ do total de colaboradores (servidores, estagiários e magistrados) responderam ao questionário Nórdico, de acordo com a Tabela 2, compreendendo parcela significativa e, portanto, conclusiva. 
Tabela 2- Quantitativo de respostas - Questionário Nórdico

\begin{tabular}{cccc}
\hline UNIDADE & RESPOSTAS & COLABORADORES/UNID. & RESPONDENTES \\
\hline Subseção 1 & 18 & 22 & $81,82 \%$ \\
Subseção 2 & 181 & 299 & $60,54 \%$ \\
Subseção 3 & 21 & 21 & $100,00 \%$ \\
Subseção 4 & 43 & 60 & $71,67 \%$ \\
Subseção 5 & 8 & 22 & $36,36 \%$ \\
Subseção 6 & 17 & 18 & $94,44 \%$ \\
Não identificado & 3 & - & - \\
TOTAL & 291 & 442 & $65,84 \%$ \\
\hline
\end{tabular}

Fonte: Elaborado pelos autores (2021).

Em relação a caracterização do servidor, a maior parte dos que responderam, cerca de 53,6\%, tem entre 34 a 49 anos, sendo considerada uma população adulta "madura". Dos 291 respondentes, 184 (63,23\%) relataram praticar atividades domésticas, assim seus corpos estão sujeitos a cargas físicas não só no ambiente de trabalho, mas no ambiente doméstico. Ainda de acordo com a pesquisa, 67\% praticam atividade física, geralmente a prática se dá de 3 a 4 vezes na semana, sendo desempenhada no período matutino em sua maioria, seguido do período noturno.

Analisando os dados referente a algum tipo de desconforto muscular, apenas $21 \%$ dos respondentes declaram possuir ou não alguma doença ou limitação de saúde que pudesse justificar alguma das dores relatadas. Uma vez que a grande maioria optou por não responder a essa questão, não se pode concluir acerca da influência das dores relatadas a possíveis problemas de saúde, sendo está uma sugestão para um futuro trabalho mais aprofundado a ser desenvolvido pelo médico do trabalho e ações da instituição.

Em relação as principais queixas de desconfortos físicos, o Gráfico 5 apresenta a totalidade de queixa, por região. 
Gráfico 5 - Principais regiões de dores reportadas

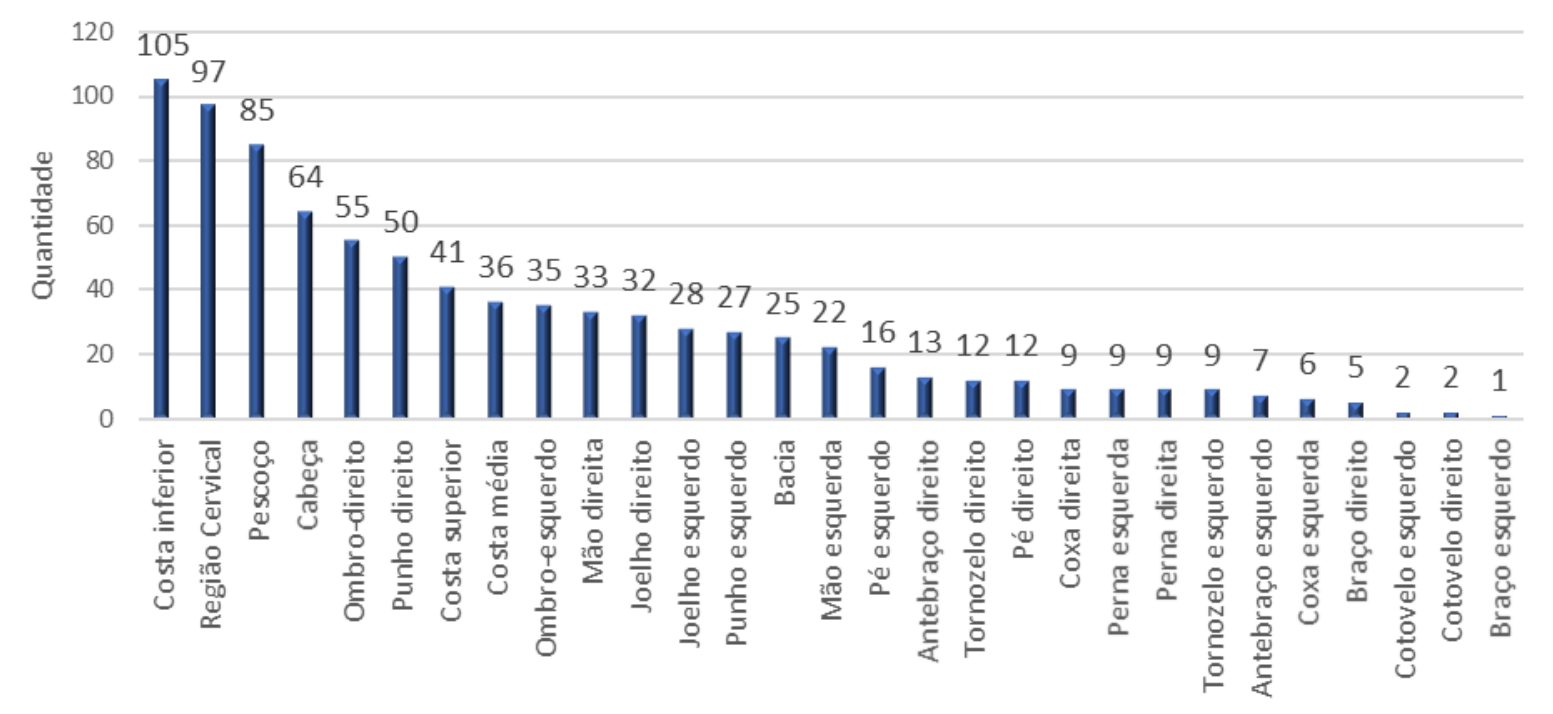

Fonte: Elaborado pelos autores (2021).

Conforme ilustrado no Gráfico 5, as principais regiões do corpo humano (que representam $80 \%$ dos relatos) são: costa inferior, região cervical, pescoço, cabeça, ombro direito, punho direito, costa superior, costa média, ombro esquerdo, joelho direito, mão direita, joelho esquerdo e punho esquerdo. Ou seja, deve-se dar mais atenção aos membros superiores e ao tronco nas ações corretivas e de prevenção de lesões. O Gráfico 6 apresenta o percentual de desconforto relatado por região do corpo.

Gráfico 6 - Principais regiões de dores reportadas por região

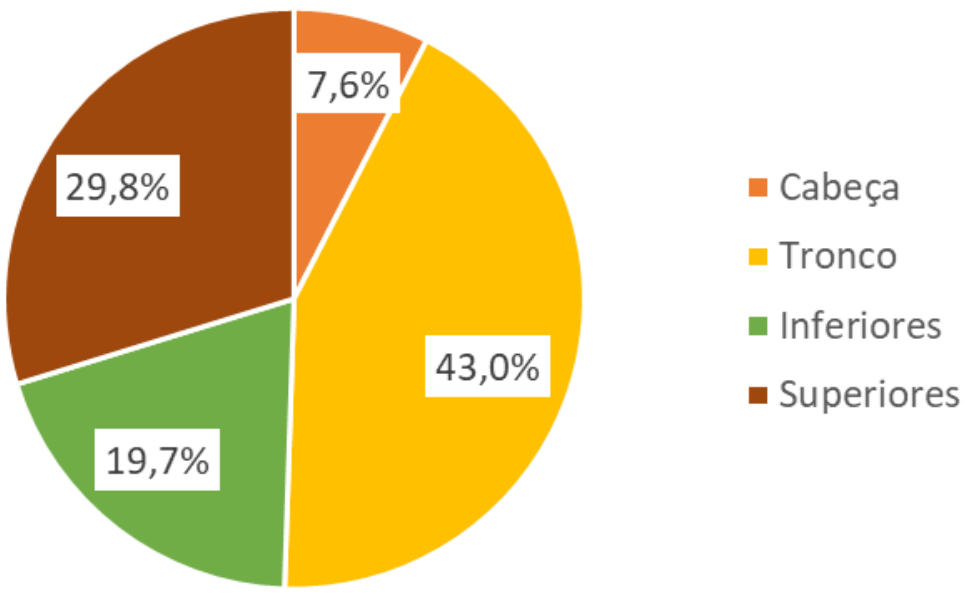

Fonte: Elaborado pelos autores (2021). 
Para a realização do Gráfico 6 considerou-se que as regiões que englobam o tronco são: Pescoço, Região Cervical, Costa superior, Costa média e costa inferior. Para os membros superiores, considerou-se os ombros, os braços, o cotovelo e antebraço, assim como punhos e mãos. A região inferior é constituída pela bacia, pernas, coxa, joelho, tornozelo e pés. E, por fim, foi considerado uma região para a cabeça.

O tronco possui $43 \%$ das reclamações, seguido dos membros superiores com $29,8 \%$. As regiões inferiores e a cabeça são os que menos obtiveram reclamações, respectivamente. Os servidores quando na aplicação os questionários relataram passar horas sentados para conseguir atingir as metas da organização e pessoais. Isso possibilita a sobrecarga das costas, região cervical, pescoço e cabeça.

No campo de preenchimento para dores ou limitações já existentes antes da pesquisa, as dores e limitações mais frequentes foram Tendinite, Artrite, Hérnia de disco, Protusão discal, Bursite e Escoliose. As principais regiões afetadas pelas limitações declaradas foram: região lombar, região cervical, joelhos e tornozelos, conforme Figura 2.

Figura 2 - Principais regiões afetadas por dores e limitações

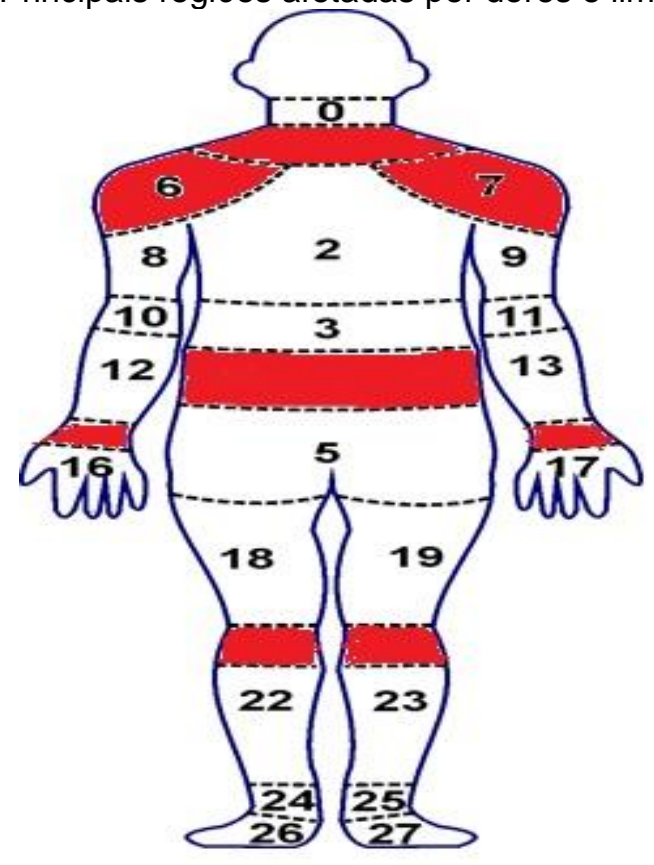

Fonte: Elaborado pelos autores (2021).

O questionário Nórdico avaliava o tempo em que o indivíduo vinha sentindo desconforto físico. O Gráfico 7 apresenta as respostas dos servidores quanto a essa 
análise. O formato do questionário padronizou as respostas para últimos 7 dias, últimos 30 dias e nos últimos 12 meses.

Gráfico 7 - Resposta dos servidores sobre quando sentiu algum desconforto relatado

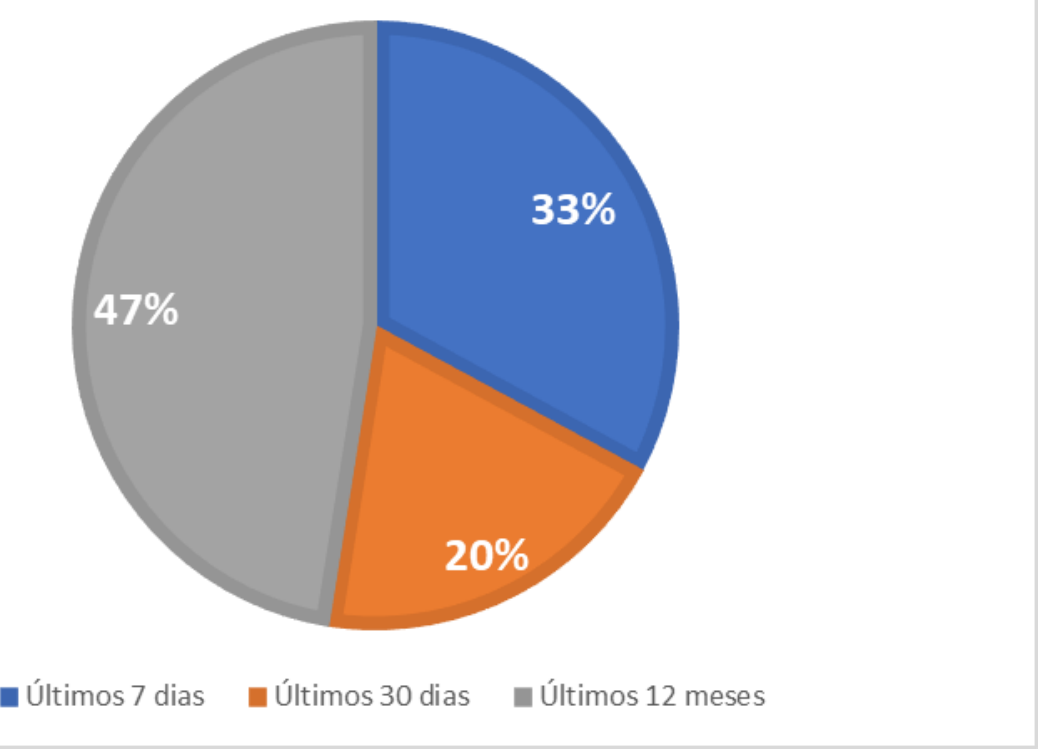

Fonte: Elaborado pelos autores (2021).

Das respostas no Gráfico 7,47\% revelou que vem sentido dores nos últimos 12 meses, tendo como referência a data de aplicação dos questionários. $20 \%$ das respostas coletadas afirmaram que vem sentido os desconfortos nos últimos 30 dias e $33 \%$ das repostas resultaram em dores musculares nos últimos 7 dias. Esses dados mostram a necessidade de acompanhamento da saúde dos servidores para impedir que os desconfortos sentidos não se tornem algum problema mais grave no decorrer do tempo.

Os tipos de desconfortos mencionados pelo corpo funcional das subseções estão no Gráfico 8. 
Gráfico 8 - Tipos de desconfortos mencionados

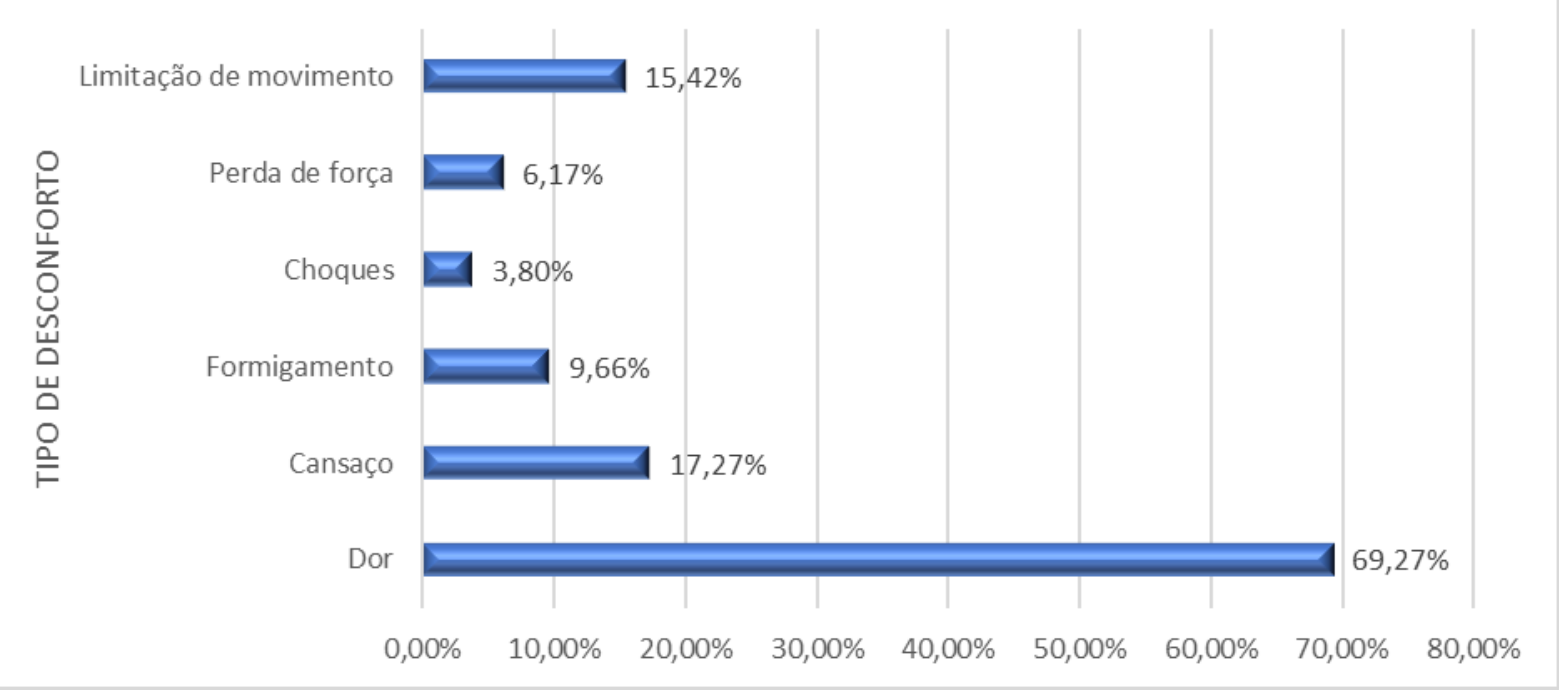

Fonte: Elaborado pelos autores (2021).

Os tipos de desconfortos são em $69,27 \%$ dos casos dores. $17,27 \%$ dos servidores relataram sentir cansaço e $15,42 \%$ relataram que o desconforto é limitação de movimento. Esses são os três primeiros que acometem os servidores e podem ajudar nos diagnósticos de possíveis problemas.

Uma das buscas realizada por meio do questionário era qual o período do dia de trabalho em que os desconfortos apareciam. O Gráfico 9 apresenta os resultados encontrados da pesquisa.

Gráfico 9 - Período em que sente mais desconfortos

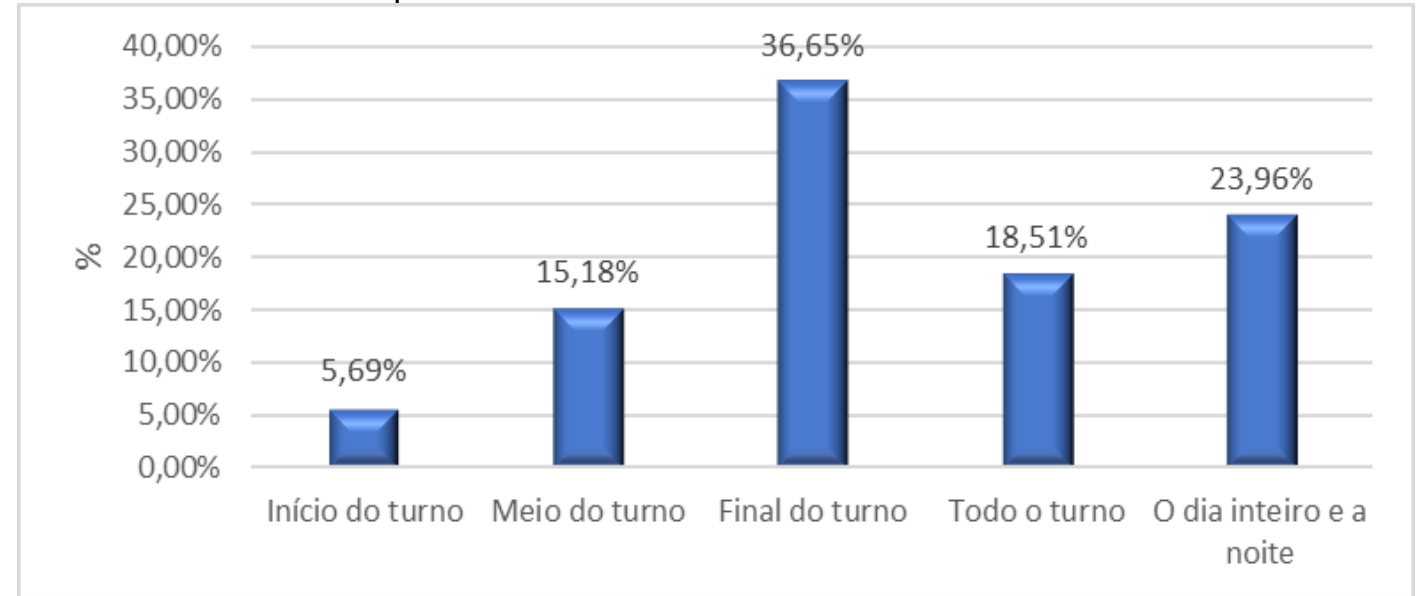

Fonte: Elaborado pelos autores (2021).

Observa-se que $36,65 \%$ dos servidores sentiram dores após o turno, o que é crítico e pode demonstrar condições de trabalho sem os padrões ergonômicos corretos. $23,96 \%$ dos colaboradores disseram sentir dores durante o dia inteiro e a 
noite, podendo já possuir uma doença muscular e estar agravando pelo não conhecimento e também por não se atentar para a ergonomia do ambiente laboral. $18,51 \%$ afirmaram sentir esses desconfortos durante todo o turno e apenas 5,69\% relataram sentir esses desconfortos já no início do turno.

Ainda sobre o questionário Nórdico, $82 \%$ falaram que a dores melhoram com o repouso e a maioria dos servidores não tomam remédios ou sequer procuraram tratamento para o desconforto físico relatado.

\section{CONSIDERAÇÕES}

A pesquisa proporcionou uma avaliação das condições ergonômicas da unidade do Tribunal Judiciário Federal e auxiliou nas elaborações de ações de melhorias. Assim, o objetivo da pesquisa foi atingido na medida em que foi possível a aplicação das ferramentas e a análise dos resultados, gerando informações acerca da situação ergonômica, no que se refere a desconfortos físicos e carga de trabalho.

Em relação aos resultados do NASA TLX, pode-se melhorar o planejamento das atividades e dos processos, melhorar a comunicação com a chefia imediata, melhorar o ambiente e clima organizacional possibilitando a troca de experiências e um ambiente aonde as pessoas não se sintam pressionadas, mesmo com metas e demandas para entrega.

Quanto a minimização dos impactos na saúde física, tem-se a melhoria dos mobiliários e periféricos, seguindo a recomendação da Norma Regulamentadora 17 Ergonomia. Além das ações de Ginástica laboral e Pilates que já acontecem, a unidade de estudo deve proporcionar intervenções constantes nos setores com Blitz postural. A conscientização de todos é primordial e deve ser feito de modo continuo, por meio de cartilhas de orientações e ações de prevenção a doenças.

\section{REFERÊNCIAS}

ABERGO, Associação Brasileira de Ergonomia. A certificação do ergonomista brasileiro Editorial do Boletim 1/2000. Associação Brasileira de Ergonomia, 2000.

ALENCAR FILHO, João Galdino de. Ergonomia: apostila. Curso de Especialização em Engenharia de Segurança do Trabalho.Recife: FESP/UPE, 1993.

ALVES M.G.M.; CHOR, D.; FAERSTEIN E.; LOPES, C.S.; WERNECK, G.L. Versão resumida da "job stress scale": adaptação para o português. Rev Saúde Pública, v. 38, n. 2, p. 164-71, 2004. https://doi.org/10.1590/S0034-89102004000200003 
BALLARDIN, L.; GUIMARÃES, L. B. M. Avaliação da carga de trabalho dos operadores de uma empresa distribuidora de derivados de petróleo. Produção, v. 19, n. 3, p. 581-592, 2009. https://doi.org/10.1590/S0103-65132009000300014

BARROS, E. N.C.; ALEXANDRE, N.M.C. Cross-cultural adaptation of the Nordic musculoskeletal questionnaire. International Nursing Review (INR), v. 50, n. 2, p.101-08, 2003. https://doi.org/10.1046/j.1466-7657.2003.00188.x

BRASIL. Ministério da Saúde. Secretaria de Vigilância em Saúde. Departamento de Vigilância em Saúde Ambiental e Saúde do Trabalhador. Dor relacionada ao trabalho: lesões por esforços repetitivos (LER): distúrbios osteomusculares relacionados ao trabalho (Dort). Brasilia: Ministério da Saúde, 2018. (Série A. Normas e Manuais Técnicos); (Saúde do Trabalhador.

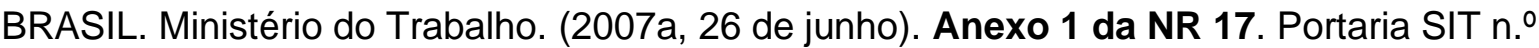
13, de 21 de junho de 2007. Brasília, DF: Diário Oficial da União.

CARDOSO, Mariane de Souza; GONTIJO, Leila Amaral. Avaliação da carga mental de trabalho e do desempenho de medidas de mensuração: NASA TLX e SWAT. Gest. Prod. São Carlos, v. 19, n. 4, p. 873-884, dez. 2012. Disponível em: http://www.scielo.br/scielo.php?script=sci arttext\&pid=S0104530X2012000400015\&lng=en\& nrm=iso. Acesso em: 20 Apr. 2021. https://doi.org/10.1590/S0104-530X2012000400015

CAVALCANTI, Leonardo Luizines de FranÇa. Um olhar ergonômico no ambiente laboral do servidor público: estudo de caso do Núcleo de Educação Física e Desportos da UFPE. 2016. 116 f. Tese (Doutorado) - Curso de Programa de Pós-graduação em Ergonomia, Universidade Federal de Pernambuco, Recife, 2016.

COLLE, H. \& REID, G.B. Context effects in subjective mental workload ratings. Human Factores, v. 40, n. 4, p. 591-600, 1998. https://doi.org/10.1518/001872098779649283

DINIZ, R. L.; GUIMARÃES, L. B. M. Avaliação da carga de trabalho mental. In: GUIMARÃES, L. B. M. Ergonomia cognitiva. Porto Alegre: FEENG, 2004.

FERRARI, Andrea Lepos. Adaptação transcultural do questionário "Cultural Study of Musculo-Skeletal and other simptoms and Associated Disability" CUPID questionnaire/ Andrea Lepos Ferrari - São Paulo, 2009

FERREIRA, M. C.; ALVES, L.; TOSTES, N. Gestão de Qualidade de Vida no Trabalho (QVT) no Serviço Público Federal: o descompasso entre problemas e práticas gerenciais. Psicologia: Teoria e Pesquisa, v. 25, n. 3, p. 319-327, 2009. https://doi.org/10.1590/S0102$\underline{37722009000300005}$

FRUTUOSO, Joselma Tavares; CRUZ, Roberto Moraes. Mensuração da carga de trabalho e sua relação com a saúde do trabalhador. Revista Brasileira de Medicina do Trabalho, Belo Horizonte, v.3, n.1, jan./jun. p. 29-36, 2005.

GUIMARÃES, L. B. M. Ergonomia cognitiva. Porto Alegre: FEENG, 2004.

HART, S. G.; STAVELAND, L. E. Development of NASA-TLX (Task Load Index): Results of empirical and theoretical research. In: HANCOCK, P. A.; MESHKATI, N. (Eds.). Human mental workload. Amsterdam: NorthHolland. p. 139-183, 1988.

http://dx.doi.org/10.1016/S0166-4115(08)62386-9. 
HASSELHORN HM, Tackenberg P, Peter R; NextStudy Group. Effort-reward imbalance among nurses in stable countries and in countries in transition. Int $\mathbf{J}$ Occup Environ Health. v.10, n. 4, p. 401-8, 2004. https://doi.org/10.1179/oeh.2004.10.4.401

IEA, Associação Internacional de Ergonomia. What is Ergonomics? Disponível em: http://www.iea.cc/01 what/What\%20is\%20Ergonomics.html. Acesso em: 11 ago. 2019.

IIDA, Itiro. Ergonomia, projeto e produção. São Paulo: Edgard Blucher LTDA, 2005.

IIDA, Itiro. Ergonomia, projeto e produção. 8.ed. São Paulo: Edgard Blücher, 2002.

KUORINKA, I. et al. Standardised Nordic questionnaires for the analysis of musculoskeletal symptoms. Appl Ergon, v. 18, p. 233-7, 1987. https://doi.org/10.1016/0003-6870(87)90010-X

LAPERUTA, Dalila Giovana Pagnoncelli et al. Revisão de ferramentas para avaliação ergonômica. Revista Produção Online, Florianópolis, v. 2, n. 1, p.665-690, jan. 2018. https://doi.org/10.14488/1676-1901.v18i2.2925

LIGEIRO, Joellen. Ferramentas de avaliação ergonômica em atividades multifuncionais: a contribuição da ergonomia para o design de ambientes de trabalho. 2010. 219 f. Tese (Doutorado) - Curso de Design, Universidade Estadual Paulista Júlio de Mesquita, Bauru, 2010.

MARCONI, M. D. A.; LAKATOS, E. M. Técnicas de pesquisa: planejamento e execução de pesquisas, amostragens e técnicas de pesquisas, elaboração, análise e interpretação de dados. 3.ed. São Paulo: Atlas, 1996.

MÁSCULO, F. S.; VIDAL, M. C. R (Org.). Ergonomia: trabalho adequado e eficiente. Rio de Janeiro: Elsevier, 2011. (Abepro).

NATIONAL INSTITUTE FOR OCCUPATIONAL SAFETY AND HEALTH. Stress at work. 2004. Disponível em: https://www.cdc.gov/niosh/topics/stress/default.html. Acesso em: 18 jun. 2021.

PINHEIRO, F. A.; TRÓCCOLI, B. T.; CARVALHO, C.. Validação do Questionário Nórdico de Sintomas Osteomusculares como medida de morbidade. Revista Saúde Pública, São Paulo, v.36, n.3, p.307-312, 2002. https://doi.org/10.1590/S0034-89102002000300008

THEORELL T. The demand-control-support model for studying health in relation to the work environment: an interactive model. In: ORTH-GÓMER K, SCHNEIDERMAN N, editors.

Behavioral medicine approaches to cardiovascular disease. Mahwah, $\mathrm{NJ}$ : Lawrence Erlbaum Associates; 1996

THEORELL T. Working conditions and health. In: BERKMAN L, KAWACHI I, editors. Social epidemiology. New York: Oxford University Press, 2000.

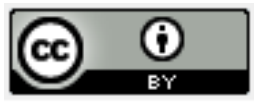

Artigo recebido em: 27/04/2021 e aceito para publicação em: 13/06/2021

DOI: http://dx.doi.org/10.14488/1676-1901.v21i2.4307 